\title{
Characterization of the Oxides Present in a Polydimethylsiloxane Layer Obtained by Polymerisation of Its Liquid Precursor in Corona Discharge
}

\author{
A. Groza and A. Surmeian \\ National Institute of Lasers, Plasma and Radiation Physics, Bucharest, 077125 Măgurele, Romania \\ Correspondence should be addressed to A. Groza; andreea@infim.ro
}

Received 20 August 2014; Accepted 28 September 2014

Academic Editor: Daniela Predoi

Copyright (C) 2015 A. Groza and A. Surmeian. This is an open access article distributed under the Creative Commons Attribution License, which permits unrestricted use, distribution, and reproduction in any medium, provided the original work is properly cited.

By combining the reflection-absorption infrared spectral studies with the peak fitting analysis we determined the type of the silicon oxides present in polydimethylsiloxane layers obtained on germanium and aluminium substrates in corona discharges. We have also evidenced that the dependence of silicon oxides density on the corona discharge current intensity is related to the existence of a concurrent anodizing process occurring at the polymer/Al substrate interface. The morphology of the Al substrate surface investigated by scanning electron microscopy proved that the anodizing process occurs.

\section{Introduction}

Polydimethylsiloxanes (PDMS) are widely used as protective corrosion media or in medical applications. The strength of the $\mathrm{Si}-\mathrm{O}$ bonds gives them a remarkable thermal stability, most oxidizing agents not being able to attack their structure. They are elastic, transparent, and compatible with human tissue and are biologically inert [1].

The PDMS layers are known for their hydrophobic character, although for biomedical applications regarding cell adhesion [2] or antibacterial activity [3] it is important that PDMS layers have a hydrophilic character. By oxygen plasma, water vapor plasma, or ultraviolet-ozone (UV-ozone) treatments their surfaces can be functionalized [4] becoming more $\mathrm{SiO}_{2}$ like surfaces with more $-\mathrm{OH}$ groups [2-5]. Recently [6], it was shown that $\mathrm{SiO}_{2}$ layers, which have an excellent compatibility with the living tissues, can be used as interlayers for improving the delamination of hydroxyapatite (HAP) [7] coatings.

In our previous papers we presented a method of generation of PDMS layers on different substrates in corona discharges starting from different liquid precursors [8-10]. In [11] we showed by Fourier transformer infrared spectroscopy, glow discharge optical emission spectroscopy, and scanning electron microscopy that function of the liquid precursor end group and substrate material, in the polymer bulk, mainly on the polymer surface, on some $\mathrm{SiO}_{2}$ like structures can be generated.

In the present work, by peak fitting analysis of the reflection-absorption infrared (IR) spectra of the PDMS layers we have investigated the type of silicon oxides formed in the polymeric layer function of corona discharge current intensity and substrate material. Also, by scanning electron microscopy (SEM) we have analyzed the morphology of the substrate surface after the complete removal of the polymer layer.

We showed that the reflection-absorption IR spectral analysis could be used for the investigation of thin films deposited on different substrates, highlighting the processes occurring at thin film/substrate interface. The understanding of these interfacial processes can be useful in the studies of the different mechanical properties of thin polymeric layers, like adherence. For example, the interlinked bonds performed by the $\mathrm{Si}-\mathrm{OH}$ groups can improve the adherence of thin layers to substrate surfaces avoiding the polymer delamination. 


\section{Materials and Methods}

In this paper, using a SP100 IR Perkin Elmer spectrometer (with a resolution of $4 \mathrm{~cm}^{-1}$ ) and a SPECTRUM acquisition software version 6.4.1, we investigated by reflection-absorption and transmission IR spectroscopy the PDMS layers deposed in corona discharges on germanium and aluminium mirror like surfaces.

The PDMS layers have been obtained in negative corona discharges in a point (cathode) to plane (anode) electrode configuration (10 $\mathrm{mm}$ interelectrodic gap) in air at atmospheric pressure for different values of current intensity $(10 \mu \mathrm{A}$ and $40 \mu \mathrm{A}$ ), starting from liquid precursors of hydroxyl terminated polydimethylsiloxane. These experimental conditions are proper for operating of the negative corona discharge in a Trichel pulse regime known for its uniformity of the current density distribution on the anode surface. Also, in this regime, the pulsating nature of the current assures uniform and periodically charged species $\left(\mathrm{O}_{2}{ }^{-}, \mathrm{O}_{3}{ }^{-}\right.$, $\mathrm{O}_{4}{ }^{-}, \mathrm{CO}_{2}{ }^{-}$, and $\mathrm{CO}_{3}{ }^{-}$) transport between electrodes [11].

The procedure of PDMS thin film generation was as follows: a drop of hydroxyl terminated PDMS lying on the plane electrode is uniformly stretched in a liquid film under the injection of the negative ions produced in corona discharge. The electrohydrodynamic instabilities induced in the liquid film determine the formation of some stationary convective structures of Bernard cell type [8]. Consequently, after 2 hours of corona charge injection on the free surface of the liquid film, a solid PDMS layer, in our case with an average thickness of few hundred of nanometers [11], is generated.

It is well known that specular techniques provide reflectance measurement for reflective materials and reflectionabsorption measurement for thin films deposited on reflective surfaces. In reflection-absorption measurements, a part of the radiation is reflected on the upper interface and contributes towards the spectrum via specular reflection. Another part of the radiation penetrates the surface film and is reflected by the reflective surface and, thus, the light passes through the surface layer twice, leading to an increase in intensity of the reflectance spectrum as compared to the normal transmission. The path length of the light through the sample depends on the angle of incidence [12].

In order to get information about the molecules bonds arrangement in the polymer layer and as close as possible to its surface, we recorded the reflection-absorption IR spectra of the PDMS layers deposited on germanium and aluminum mirror like surfaces using a variable angle specular reflectance accessory positioned inside the IR spectrometer. This accessory allows the variation of the angle of incidence of the light on the sample. The path length of the light and consequently the penetration depth of the light into the layer can be changed by varying the angle of incidence light on the sample. The reflection-absorption measurements were performed by varying the angle of reflection in the range of $30^{\circ}-60^{\circ}$ [13].

The acquired reflection-absorption and transmission IR spectra were transformed into absorption spectra according to the formulas $A=\log (1 / R)$ and $A=\log (1 / T)$, respectively, using the SPECTRUM software.
In order to better reveal the structure of the obtained absorption spectra of the PDMS layers we proceed with the peak fitting analysis performed using the MagicPlotPro software specialized for these kinds of investigations in accordance with the National Institute of Standard and Technology (NIST) [22]. The procedure consists in a baseline correction of experimental IR spectrum followed by the calculation of the second order derivative for peak wavenumbers identification.

For each identified peak we used a Lorentz type profile curve as fitted curve. In the peak fitting analysis process, a sum of all the Lorentz fitted curves is generated by multiple iteration of the nonlinear least squares data fitting algorithm of the software. If the sum of all the fitted curves is set correctly the algorithm gives a valid and convergent solution. The theoretical curve, obtained as a result of peak fitting analysis versus experimental IR curve, will be presented and analysed in our further discussions.

\section{Results and Discussions}

Our previous papers have shown that, during the polymerization process of hydroxyl terminated polydimethylsiloxane liquid precursors in corona discharges, some $\mathrm{SiO}_{2}$ like structures are generated. The morphology of these layers deposited on different substrates and their elemental depth profiles [11] showed that the $\mathrm{SiO}_{2}$ structures are formed in the polymer bulk, mainly on the polymer surface.

In this work, the silicon oxides type in the polymeric layer was revealed by the peak fitting analysis of their reflectionabsorption IR spectra. Also, the influence of the anodization process of the substrate on the IR reflection-absorption spectra of the PDMS layers will be analyzed.

\subsection{FT-IR Analysis of Polymers Generated on Germanium} Substrates. The IR spectra of the PDMS layer generated on a Ge substrate in corona discharge for an intensity of the current of $10 \mu \mathrm{A}$ are presented in Figure 1. Although there are some differences, both reflection-absorption, Figure 1(a), and transmission, Figure 1(b), spectra indicate the same IR bands specific to PDMS layers: 860 and $792 \mathrm{~cm}^{-1}$ peaks attributed to $\mathrm{Si}-\mathrm{CH}_{3}$ rocking and $\mathrm{Si}-\mathrm{C}$ stretching vibrations; 1400 and $1254 \mathrm{~cm}^{-1}$ peaks assigned to symmetrical and asymmetrical deformation of $\mathrm{CH}_{3}$ bonds in $\mathrm{Si}-\mathrm{CH}_{3}$ groups; 1080 and $1015 \mathrm{~cm}^{-1}$ peaks belonging to $\mathrm{Si}-\mathrm{O}-\mathrm{Si}$ stretching vibrations [15].

Knowing germanium as a transparent material to the IR light, we record the transmission IR spectrum of the PDMS layer as a marker for a proper identification of the absorption bands from 870,570 , and $750 \mathrm{~cm}^{-1}$ belonging to $\mathrm{Ge}-\mathrm{O}-$ $\mathrm{Ge}$ and $\mathrm{Ge}-\mathrm{OH}$ vibrational groups $[10,20]$. The decrease of the intensity of these absorption bands in the reflectionabsorption IR spectrum, Figure 1(a), is accompanied by the increases of the $\mathrm{Si}-\mathrm{O}-\mathrm{Ge}$ IR band from $660 \mathrm{~cm}^{-1}$ [10] and the evidence of the $\mathrm{Si}-\mathrm{OH}$ IR band from $\sim 960 \mathrm{~cm}^{-1}$ [18]. As the elemental depth profile of a PDMS layers deposited on a Ge substrate previously showed the presence of a germanium oxide at the polymer/substrate interface [10], we suppose 


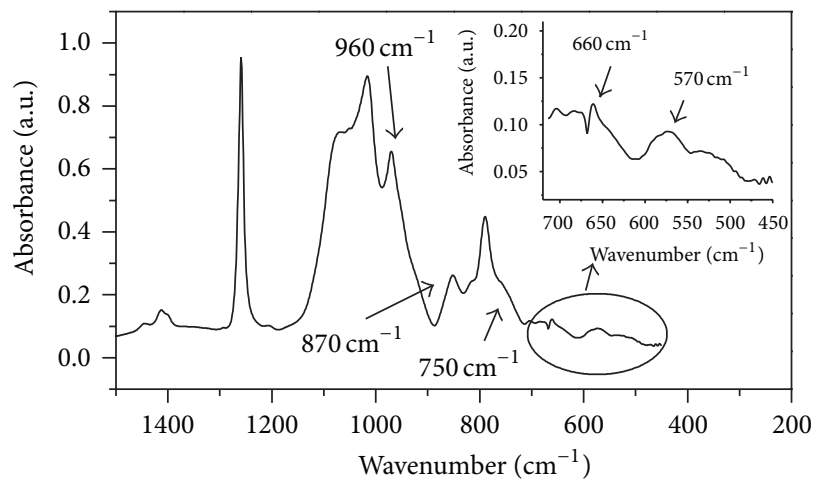

(a)

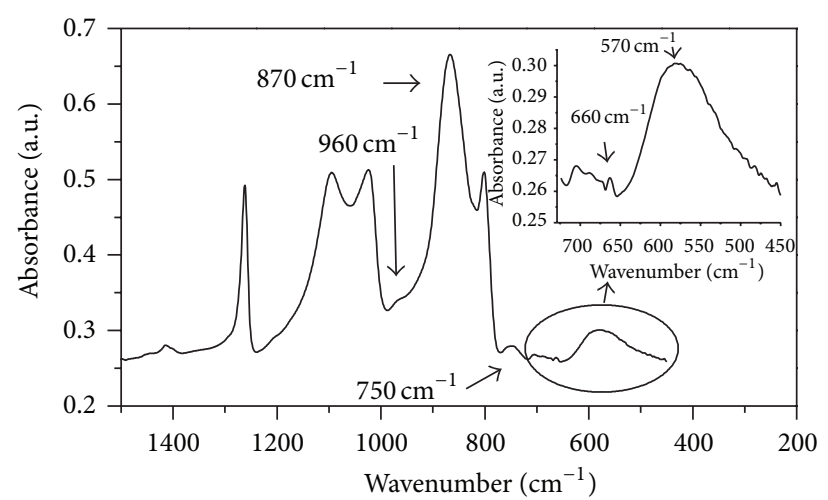

(b)

FIGURE 1: IR spectrum of the PDMS layer obtained by (a) reflection-absorption spectroscopy for a reflection angle of $30^{\circ}$ and (b) transmission spectroscopy.

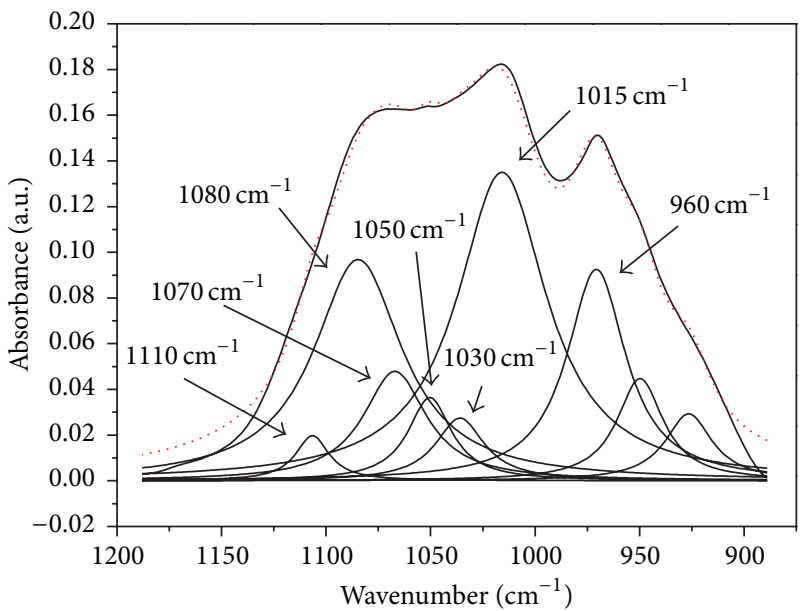

(a)

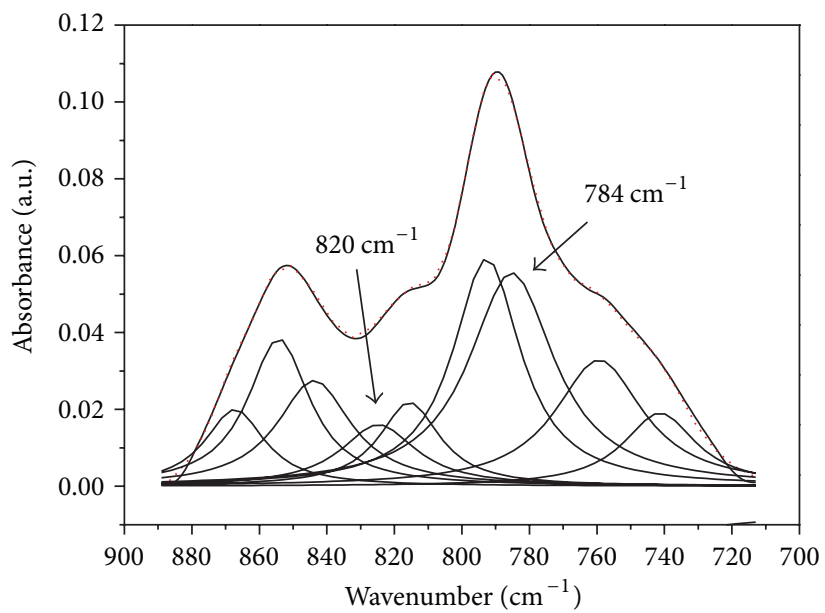

(b)

FIGURE 2: Deconvoluted reflection-absorption IR spectra (30 reflection angle) of PDMS layers deposited on Ge substrate in the spectral regions: (a) $1200-900 \mathrm{~cm}^{-1}$ and (b) $900-700 \mathrm{~cm}^{-1}$. The experimental curve is plotted in black and the theoretical fitted curve is in red dotted line.

that the IR spectrum obtained for $30^{\circ}$ reflection angle can give information about the processes that take place at polymer/substrate interface.

Besides the evidence of the $\mathrm{Si}-\mathrm{O}-\mathrm{Ge}$ interlinked bonds between the polymer layer and the germanium substrate, the strong absorption band of the $\mathrm{Si}-\mathrm{OH}$ groups present in the reflection-absorption IR spectrum, Figure 1(a), indicates the possibility of the development of some additional processes in the polymer layer, other than the polymerization one.

Therefore, we performed a peak fitting analysis for certain spectral regions of the reflection-absorption IR spectrum from Figure 1(a). This analysis reveals the formation of a $\mathrm{SiO}_{2}$ network with some specific $\mathrm{SiO}_{0.5}, \mathrm{SiO}_{1.5}$, and $\mathrm{SiO}_{4}$ structures in the polymer layer, as is shown in Figure 2 and Table 1.

\subsection{FT-IR Analysis of Polymers Generated on Aluminum} Substrates. The PDMS layers deposited on $\mathrm{Al}$ substrates in negative corona discharges for $10 \mu \mathrm{A}$ and $40 \mu \mathrm{A}$ values of the discharge current are investigated by reflection-absorption spectroscopy. The peak fitting analysis of the IR spectra obtained for different reflection angles of the light from the sample allowed us to evidence the silicon oxides type: at polymer/Al substrate interface, into the polymer bulk, and as close as possible to its surface, as function of corona discharge current intensity.

In Figure 3 and Table 1 the results of the peak fitting analysis of the IR spectra of the PDMS layer deposited on Al substrate for a value of the corona discharge current of $10 \mu \mathrm{A}$ are presented. It can be seen that in the spectra of PDMS layers deposited on $\mathrm{Al}$ and $\mathrm{Ge}$ substrates are identified as the same types of silicon oxides.

Looking carefully at the evolution of the IR bands specific to silicon oxides developed in the PDMS layer function of the reflection angle, Table 1, we can find out the distribution of these structures in the PDMS layer. There are no major increases in the intensities of the IR bands characteristic to 


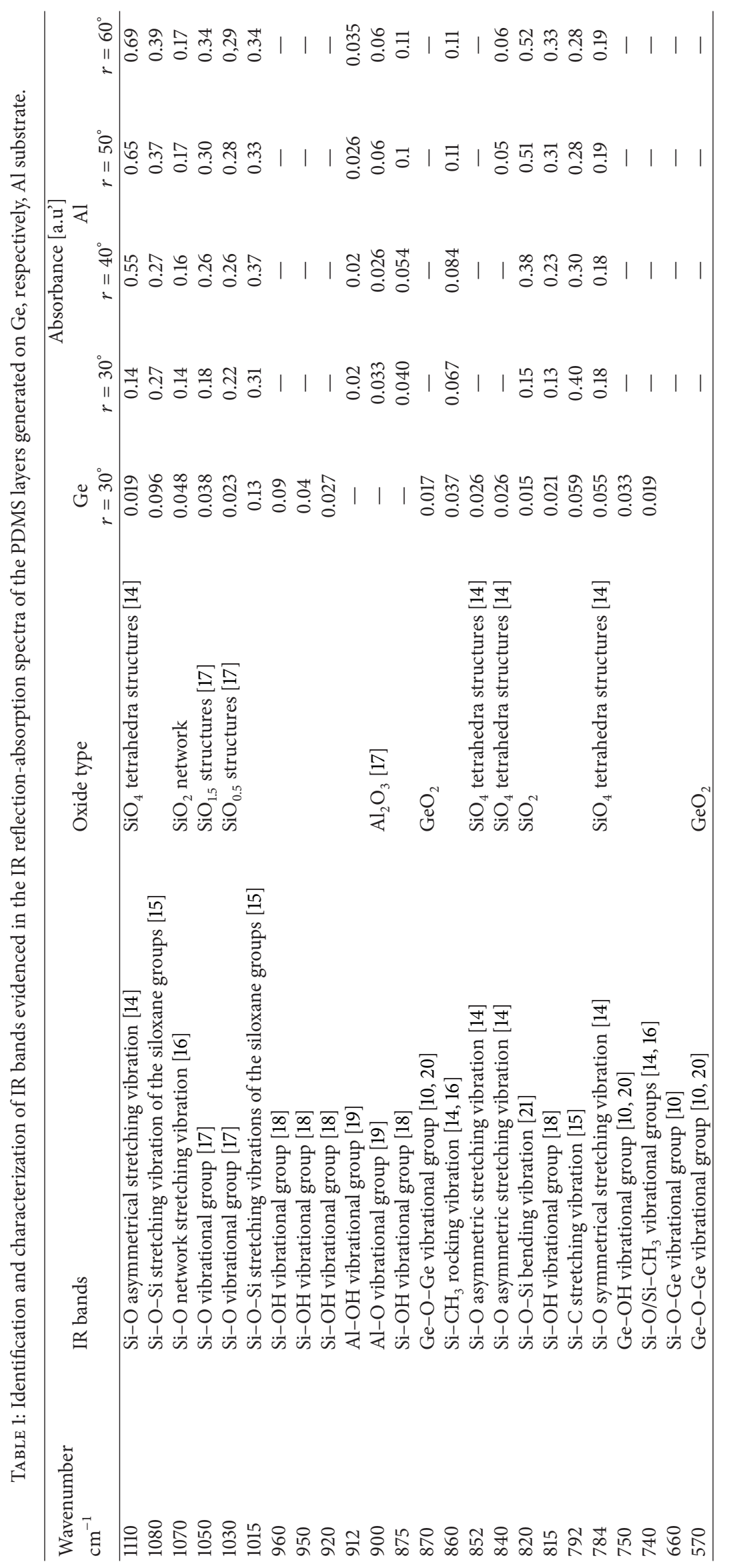



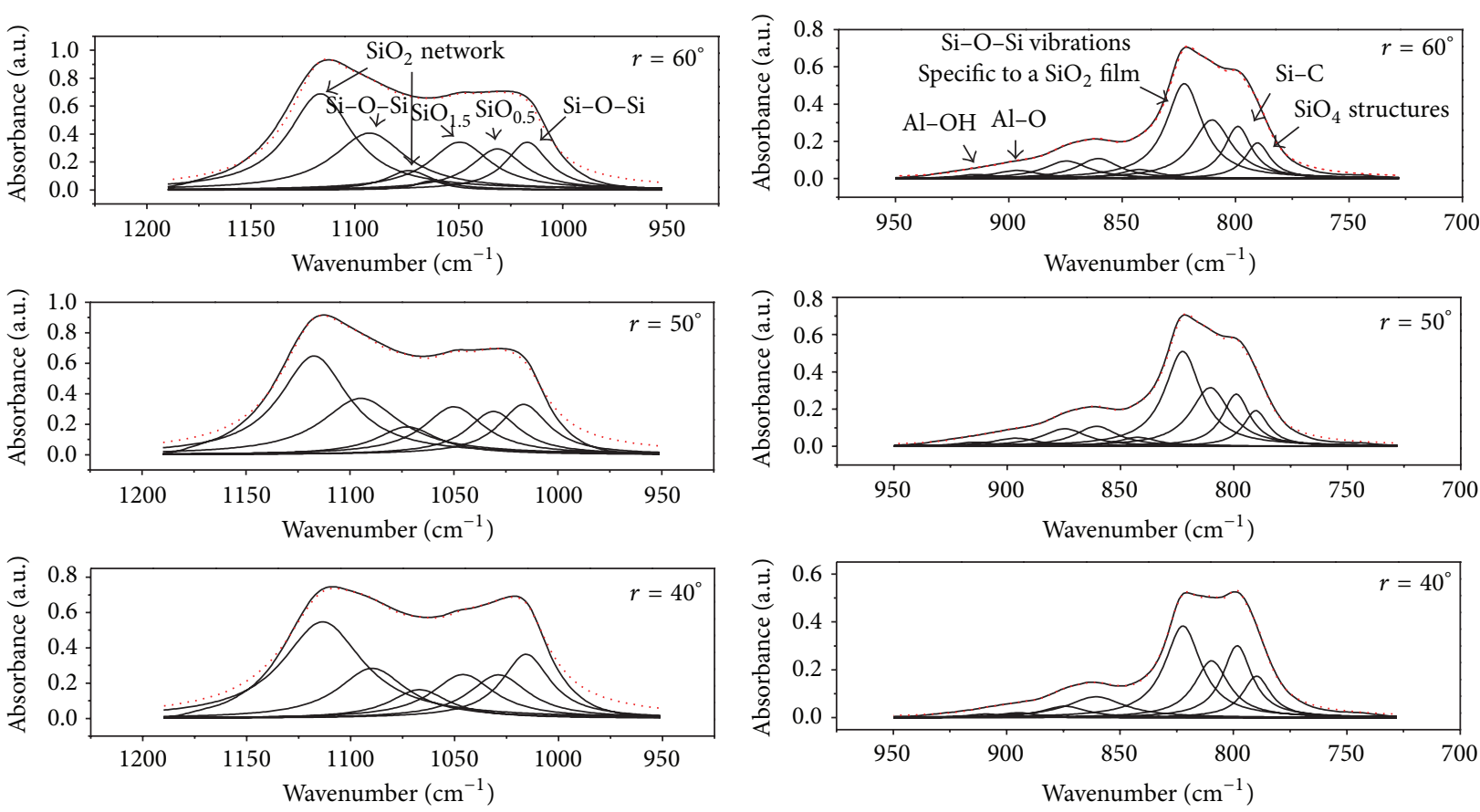

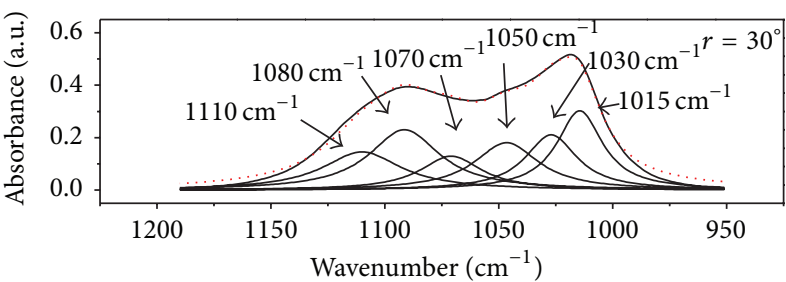

(a)

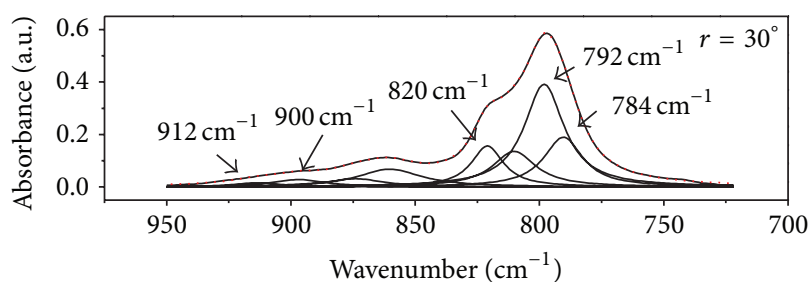

(b)

FIGURE 3: The dependence of the deconvoluted IR reflection-absorption spectra of PDMS layers deposited on Al substrate on the reflection angle in (a) $1200-900 \mathrm{~cm}^{-1}$ and (b) $900-700 \mathrm{~cm}^{-1}$ spectral regions.

siloxane groups ( 1080 and $1015 \mathrm{~cm}^{-1}$ ), $\mathrm{SiO}_{0.5}, \mathrm{SiO}_{1.5}$ suboxides (1050 and $\left.1030 \mathrm{~cm}^{-1}\right)$, and $\mathrm{SiO}_{4}\left(784 \mathrm{~cm}^{-1}\right)$ structures. This fact indicates that the polymerization process of PDMS liquid film and that of the silicon oxides generation in corona discharge are produced homogeneously.

The intensities of the 1110 and $820 \mathrm{~cm}^{-1}$ (specific to stoichiometric $\mathrm{SiO}_{2}$ layers [21]) IR bands increase gradually with the reflection angle mainly due to the higher density of $\mathrm{SiO}_{4}$ structures formed at polymer surface as the scanning electron microscopy measurements previously showed [11]. In [16], the $\mathrm{Si}-\mathrm{O}$ vibrations manifested at $1110 \mathrm{~cm}^{-1}$ and $1070 \mathrm{~cm}^{-1}$ were attributed to a cage like $\mathrm{Si}-\mathrm{O}$ stretching mode and, respectively, to a $\mathrm{Si}-\mathrm{O}$ network stretching mode that appears in a $\mathrm{SiO}_{2}$ network. As the IR bands from $1070 \mathrm{~cm}^{-1}$ and $784 \mathrm{~cm}^{-1}$ do not present a gradual increase with the reflection angle, it means that at the proximity of the surface a cage like network of $\mathrm{SiO}_{4}$ structures formation is favored. The results presented in Figure 3(b) and Table 1 also indicate that the intensity of the Si-OH IR band at $875 \mathrm{~cm}^{-1}$ increases as we increase incrementally the reflection angle from $30^{\circ}$ to $60^{\circ}$. In some previous papers [18] it was shown that the formation of the $\mathrm{OH}$ groups on the surface of PDMS layers increases the bioactivity properties of these materials, making them more proper for biological applications.

The distribution of the Si-O based network in the polymer can be explained if we consider the negatively charged particles deposition at the free surface of the liquid precursor during the polymerization process of the hydroxyl terminated PDMS in corona discharge. The negative ions of oxygen $\mathrm{O}_{2}^{-}, \mathrm{O}_{3}^{-}, \mathrm{O}_{4}^{-}, \mathrm{CO}_{2}^{-}$, and $\mathrm{CO}_{3}{ }^{-}$and water vapors from the atmosphere [23] are then continuously and uniformly injected into the liquid precursor generating a convective movement of the liquid. In this way, they propagate through the liquid until reaching the substrate. As a result of these processes, the charged particles attack like solvents the chemical structure of the precursor initiating a polymerization process. As the polymerization process advances and the convective movement of the liquid is diminished, the charge particle deposition from the free surface of the material favors the $\mathrm{SiO}_{4}$ structures formation mainly at the polymer surface [11].

The presence of the polymers deposited on both Ge and $\mathrm{Al}$ substrates of the $\mathrm{Si}-\mathrm{OH}, \mathrm{Ge}-\mathrm{OH}, \mathrm{Al}-\mathrm{OH}, \mathrm{Si}-\mathrm{O}-\mathrm{Si}, \mathrm{Ge}-$ $\mathrm{O}-\mathrm{Ge}, \mathrm{Al}-\mathrm{O}-\mathrm{Al}$, and $\mathrm{Si}-\mathrm{O}-\mathrm{Ge}$ groups in the IR spectra may be considered as a result of the following reactions occurring 
in the polymer, respectively $[10,11,24]$ :

$$
\begin{gathered}
\mathrm{H}_{2} \mathrm{O}+\mathrm{Si}-\mathrm{O}-\mathrm{Si}=\mathrm{Si}-\mathrm{O}-\mathrm{H}+\mathrm{H}-\mathrm{O}-\mathrm{Si} \\
\mathrm{Si}-\mathrm{OH}+\mathrm{Si}-\mathrm{OH}=\mathrm{Si}-\mathrm{O}-\mathrm{Si}+\mathrm{H}_{2} \mathrm{O} \\
\mathrm{Al}-\mathrm{OH}+\mathrm{Al}-\mathrm{OH}=\mathrm{Al}-\mathrm{O}-\mathrm{Al}+\mathrm{H}_{2} \mathrm{O} \\
\mathrm{Si}-\mathrm{OH}+\mathrm{Ge}-\mathrm{OH}=\mathrm{Si}-\mathrm{O}-\mathrm{Ge}+\mathrm{H}_{2} \mathrm{O} \\
\mathrm{Ge}-\mathrm{OH}+\mathrm{Ge}-\mathrm{OH}=\mathrm{Ge}-\mathrm{O}-\mathrm{Ge}+\mathrm{H}_{2} \mathrm{O}
\end{gathered}
$$

Although the PDMS layers are produced in the same experimental conditions on both $\mathrm{Ge}$ and $\mathrm{Al}$ substrates $(10 \mu \mathrm{A}$ current intensity of the corona discharge), there are no Si$\mathrm{O}-\mathrm{Al}$ vibrational bands identified in the IR spectrum from Figure 3.

During the polymerization process of the hydroxyl terminated PDMS liquid precursor in negative corona discharge some water molecules are generated. They can be decomposed under the influence of corona electric fields and associated charge injection, generating $\mathrm{OH}$ radicals. Thus, the negative ions of oxygen produced in corona discharge and the $\mathrm{OH}$ radicals present in the material bulk can oxidize the substrate surface generating oxides by a process similar to anodization [25]. In a classical electrochemical anodization process, these species are responsible for the oxidation of the material interface and the generation of oxides.

The IR spectra of a PDMS layer deposited on $\mathrm{Al}$ substrate in a negative corona discharge for a discharge current of $40 \mu \mathrm{A}$ are presented in Figure 4. As we increase the reflection angle from $30^{\circ}$ to $60^{\circ}$ the IR spectra look alike. Although in Figure 4 there are no visible IR bands attributed to $\mathrm{Si}-\mathrm{O}$ bonds, other than those specific to siloxane groups, the peak fitting analysis allowed the identification of the IR bands characteristic to the $\mathrm{SiO}_{2}$ network. The distribution of these IR bands (for all the reflection angles) is similar to that one presented in Figure 3 in the case of the PDMS layer deconvoluted spectra from $30^{\circ}$ reflection angle. This fact could indicate that some concurrent processes that inhibit the major development of the $\mathrm{SiO}_{2}$ network on the polymer layer surface have occurred during the polymerization of the PDMS.

The IR band from $642 \mathrm{~cm}^{-1}$, previously assigned to $\mathrm{Si}-\mathrm{O}-$ Al bonds formation [11,26], appears in the spectra in Figure 4, having almost the same intensity for all the reflection angles. This band was not observed in the IR spectrum of the PDMS layer generated on $\mathrm{Al}$ substrate for a value of the corona discharge current of $10 \mu \mathrm{A}$. It indicates that, at higher values of the corona discharge currents $(40 \mu \mathrm{A}), \mathrm{Si}-\mathrm{OH}$ bonds are rather involved in the generation of $\mathrm{Si}-\mathrm{O}-\mathrm{Al}$ bonds than in the formation of the silicon oxides.

The dependence of the Si-O-Al IR band intensity on the corona discharge current values observed for a reflection angle of $30^{\circ}$ was previously associated with an anodization process of the $\mathrm{Al}$ substrate at polymer/substrate interface. The aluminum oxide layer formed at polymer/substrate interface was evidenced by the elemental depth profile of the PDMS layer deposited on an $\mathrm{Al}$ substrate for $10 \mu \mathrm{A}$ corona discharge current intensity [11].

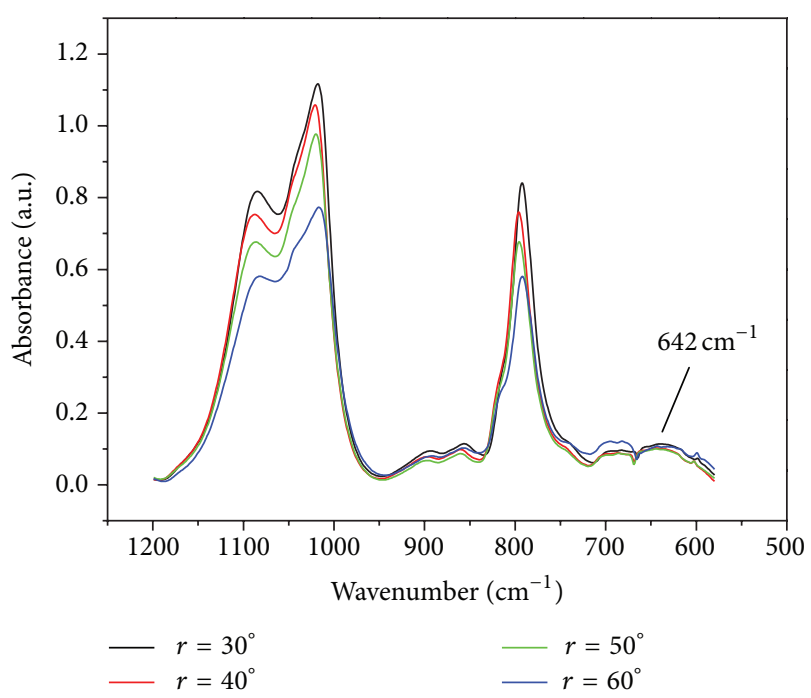

FIGURE 4: IR reflection-absorption spectra of the PDMS layer deposited on $\mathrm{Al}$ substrate (at $40 \mu \mathrm{A}$ discharge current) for different reflection angles.

Therefore, we suppose that the similar values of the $\mathrm{Si}-$ $\mathrm{O}-\mathrm{Al}$ IR band intensities obtained when the reflection angle was gradually increased up to $60^{\circ}$ (for $40 \mu \mathrm{A}$ corona discharge current), Figure 4, could indicate an advanced anodization of the substrate with the formation of some columnar structures [24]. Thus, as the polymer is formed, it follows perfectly the complex surface of the anodized $\mathrm{Al}$ interface and the $\mathrm{Si}-\mathrm{O}-\mathrm{Al}$ bonds are uniformly distributed inside the polymer bulk.

The presence of the $\mathrm{Si}-\mathrm{O}-\mathrm{Al}$ bonds in the IR spectrum, Figure 4, indicates that the $\mathrm{Si}-\mathrm{OH}+\mathrm{Al}-\mathrm{OH}=\mathrm{Si}-\mathrm{O}-\mathrm{Al}+$ $\mathrm{H}_{2} \mathrm{O}$ reaction is also possible to occur in the PDMS layer.

3.3. Scanning Electron Microscopy (SEM) Investigation of the Al Substrate Surfaces. The surface morphology of the substrate, after the complete removal of the polymers obtained at two different corona discharge current intensities, was examined using the scanning electron microscopy (SEM). Images were acquired with a FEI Inspect $S$ scanning electron microscope in both high-vacuum and low-vacuum modes.

In Figure 5(a) it can be seen that, for $10 \mu \mathrm{A}$ intensity of the corona discharge current, the anodized $\mathrm{Al}$ surface is rugged with no defined pore structures. On the contrary, when the corona discharge current is increased up to $40 \mu \mathrm{A}$, Figure $5(\mathrm{~b})$, the distribution and shape of the pores are changed. Their structure is ordered indicating some columns formation into the material bulk.

These SEM results are in good agreement with the IR spectral analysis shown in Figure 3. In this way, as the polymer is formed it follows the porous surface of the anodized Al substrate, with the $\mathrm{Si}-\mathrm{O}-\mathrm{Al}$ bonds being distributed uniformly into the polymer bulk.

The morphology of the $\mathrm{Al}$ surfaces also indicates that the infusion of negative oxygen ions and oxygen based radicals generated in negative corona discharge during the polymerization processes of a PDMS liquid precursor is not limited to 


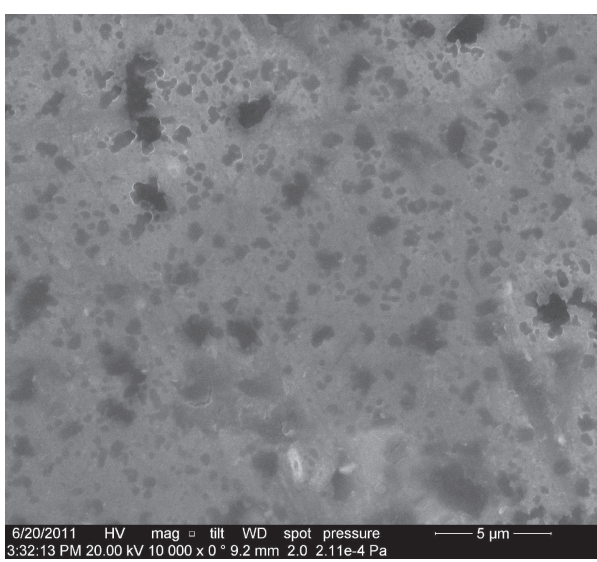

(a)

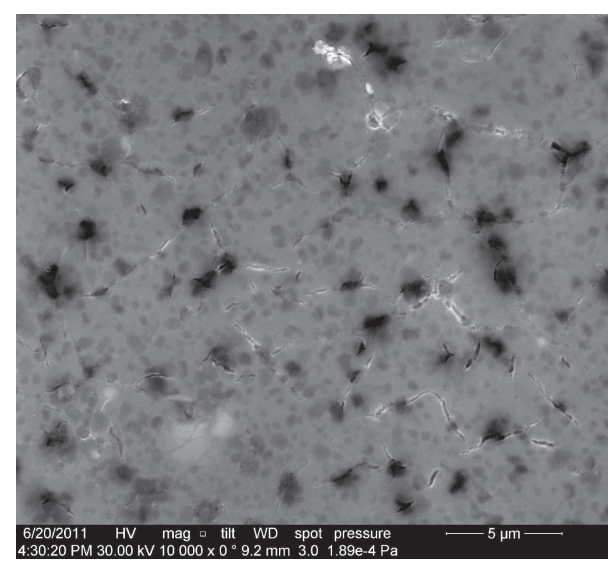

(b)

FIGURE 5: SEM images of the anodized Al substrate surface at different corona discharge current intensities: (a) $I=10 \mu \mathrm{A}$ and (b) $I=40 \mu \mathrm{A}$.

the polymer surface and polymer bulk, respectively. They can attack directly and indirectly (due to the $\mathrm{OH}$ radicals generated into the polymer bulk) the surface of the substrate material by an oxidation process similar to anodization [11,25].

We did not observe these kinds of structures on the surface of oxidized germanium substrate.

\section{Conclusions}

The studies performed by reflection-absorption IR spectroscopy coupled with the peak fitting analysis presented in this paper evidenced the type of the silicon oxides structures in the PDMS layer deposed on different supports in corona discharges. At low current intensity of the corona discharge $(10 \mu \mathrm{A})$, the IR spectral analysis of the layers deposed on germanium and aluminium substrates showed that while the $\mathrm{SiO}_{0.5}, \mathrm{SiO}_{1.5}$ suboxides and $\mathrm{SiO}_{4}$ structures are uniformly distributed in the polymer layer, the cage like network of the $\mathrm{SiO}_{4}$ structures is more present in the very proximity of the polymer surface. The germanium and aluminium oxides were also evidenced.

As the distribution of silicon oxides structures in the PDMS layer deposed on aluminium substrate is strongly dependent on the corona discharge current intensity, we observed that at high currents $(40 \mu \mathrm{A})$ their distribution is influenced by the anodization of the $\mathrm{Al}$ substrate.

The SEM images of the Al substrate surface after the complete removal of the polymers indicate the presence of the porous alumina structures which create the possibility of columns formation into the material bulk. These images evidenced the anodization process of the Al substrate confirming the results obtained by reflection-absorption IR spectral analysis of the PDMS layer.

\section{Conflict of Interests}

The authors declare that there is no conflict of interests regarding the publication of this paper.

\section{Acknowledgment}

This work was supported by the PT-PCCA-2011-3.1-1136 UEFISCDI project.

\section{References}

[1] S. Pinto, P. Alves, C. M. Matos et al., "Poly(dimethyl siloxane) surface modification by low pressure plasma to improve its characteristics towards biomedical applications," Colloids and Surfaces B: Biointerfaces, vol. 81, no. 1, pp. 20-26, 2010.

[2] D. Fuard, T. Tzvetkova-Chevolleau, S. Decossas, P. Tracqui, and P. Schiavone, "Optimization of poly-di-methyl-siloxane (PDMS) substrates for studying cellular adhesion and motility," Microelectronic Engineering, vol. 85, no. 5-6, pp. 1289-1293, 2008.

[3] P. Ferreira, Á. Carvalho, T. R. Correia, B. P. Antunes, I. J. Correia, and P. Alves, "Functionalization of polydimethylsiloxane membranes to be used in the production of voice prostheses," Science and Technology of Advanced Materials, vol. 14, no. 5, Article ID 055006, 2013.

[4] J. C. Selby and M. A. Shannon, "A method to fabricate mesoscopic freestanding polydimethylsiloxane membranes used to probe the rheology of an epithelial sheet," Journal of Biochemical and Biophysical Methods, vol. 70, no. 6, pp. 932-944, 2008.

[5] P. Ingram, M. Im, S. McDermott, M. Wicha, and E. Yoon, "Spheroid cell culture on PDMS hydrophobic surfaces and integration into microfludic devices," in Proceedings of the International Conference on Miniaturized Systems for Chemistry and Life Sciences (MicroTAS '11), pp. 1539-1541, Seattle, Wash, USA, October 2011.

[6] K. Mediaswanti, C. Wen, E. P. Ivanova, C. C. Berndt, and J. Wang, "Sputtered hydroxyapatite nanocoatings on novel titanium alloys for biomedical applications," in Titanium Alloys Advances in Properties Control, chapter 1, INTECH, 2013.

[7] S. L. Iconaru, P. Chapon, P. Le Coustumer, and D. Predoi, "Antimicrobial activity of thin solid films of silver doped hydroxyapatite prepared by sol-gel method," The Scientific World Journal, vol. 2014, Article ID 165351, 8 pages, 2014. 
[8] A. Groza, A. Surmeian, M. Ganciu, and I. I. Popescu, "Infrared spectral investigation of organosilicon compounds under corona charge injection in air at atmospheric pressure," Journal of Optoelectronics and Advanced Materials, vol. 7, no. 5, pp. 2545-2548, 2005.

[9] A. Groza, A. Surmeian, M. Ganciu, R. Medianu, and I. I. Popescu, " $\mathrm{SIO}_{2}$ - Like thin films generation in corona discharges in air at atmospheric pressure: IR spectroscopy and atomic force microscopy investigations," Journal of Optoelectronics and Advanced Materials, vol. 7, no. 4, pp. 2159-2164, 2005.

[10] A. Groza, A. Surmeian, C. Diplasu, M. Ganciu, P. Chapon, and I. I. Popescu, "Spectral investigations of the processes observed at polydimetylsiloxane polymer-substrate interface during its polymerization process in negative and positive corona discharges," Journal of Optoelectronics and Advanced Materials, vol. 12, no. 11, pp. 2311-2314, 2010.

[11] A. Groza, A. Surmeian, C. Diplasu et al., "Physico-chemical processes occurring during polymerization of liquid polydimethylsiloxane films on metal substrates under atmospheric pressure air corona discharges," Surface and Coatings Technology, vol. 212, pp. 145-151, 2012.

[12] Z. M. Khoshhesab, "Reflectance IR Spectroscopy," in Infrared Spectroscopy-Materials Science, Engineering and Technology, T. Theophanides, Ed., chapter 11, pp. 233-244, InTech, 2012.

[13] http://www.vscht.cz/anl/vibspec/FTIR\%20Reflection\%20Techniques.pdf.

[14] B. J. Saikia, G. Parthasarathy, and N. C. Sarmah, "Fourier transform infrared spectroscopic estimation of crystallinity in $\mathrm{SiO}_{2}$ based rocks," Bulletin of Materials Science, vol. 31, no. 5, pp. 775$779,2008$.

[15] D. Lin-Vien, N. B. Colthup, W. G. Fateley, and J. G. Grasselli, "Organosilicon compounds," in The Handbook of Infrared and Raman Characteristic Frequency of Organic Molecules, pp. 251261, Academic Press, San Diego, Calif, USA, 1991.

[16] S. W. Hwang, G. R. Lee, J. H. Min et al., "Etch characteristics of silsesquioxane-based low dielectric constant material in fluorocarbon plasma," Japanese Journal of Applied Physics, vol. 41, no. 9, pp. 5782-5786, 2002.

[17] J. Lambers and P. Hess, "Infrared spectra of photochemically grown suboxides at the $\mathrm{Si} / \mathrm{SiO}_{2}$ interface," Journal of Applied Physics, vol. 94, no. 5, pp. 2937-2941, 2003.

[18] A. C. M. Kuo, "Poly(dimethylsiloxane)," in Polymer Data Handbook, J. E. Mark, Ed., pp. 411-435, Oxford University Press, 1999.

[19] S. Wei, L. Wen, and H. Y. Hua, "FTIR analysis of adsorption of polydiallyl-dimethyl-ammonium chloride on kaolinite," Journal of Central South University of Technology, vol. 15, pp. 373377, 2008.

[20] R. F. S. Lenza and W. L. Vasconcelos, "Preparation of silica by sol-gel method using formamide," Materials Research, vol. 4, no. 3, pp. 189-194, 2001.

[21] X. L. Wu, T. Gao, G. G. Siu, S. Tong, and X. M. Bao, "Defectrelated infrared photoluminescence in $\mathrm{Ge}^{+}$-implanted $\mathrm{SiO} 2$ films," Applied Physics Letters, vol. 74, no. 17, pp. 2420-2422, 1999.

[22] "MagicPlot 2.5.1 Usr Guide," Magicplot Systems, LLC, 2013, http://magicplot.com/downloads.php.

[23] M. Goldman and A. Goldman, "Corona discharges," in Gaseous Electronics, M. N. Hirsh and H. J. Oskam, Eds., vol. 1, pp. 219290, Academic Press, New York, NY, USA, 1978.
[24] B. J. G. de Aragão and Y. Messaddeq, "Peak separation by derivative spectroscopy applied to FTIR analysis of hydrolized silica," Journal of the Brazilian Chemical Society, vol. 19, no. 8, pp. 1582-1594, 2008.

[25] X. Zhao, S.-K. Seo, U.-J. Lee, and K.-H. Lee, "Controlled electrochemical dissolution of anodic aluminum oxide for preparation of open-through pore structures," Journal of the Electrochemical Society, vol. 154, no. 10, pp. C553-C557, 2007.

[26] Y. Y. Ivanova, T. I. Gerganova, M. H. V. Fernandes, and I. M. M. Salvado, "Preparation of nanostructured porous $\mathrm{SiO}_{2}$ $\mathrm{Al}_{2} \mathrm{O}_{3}$ oxycarbonitride materials obtained by a new chemical precursor method," Central European Journal of Chemistry, vol. 7, no. 1, pp. 42-46, 2009. 

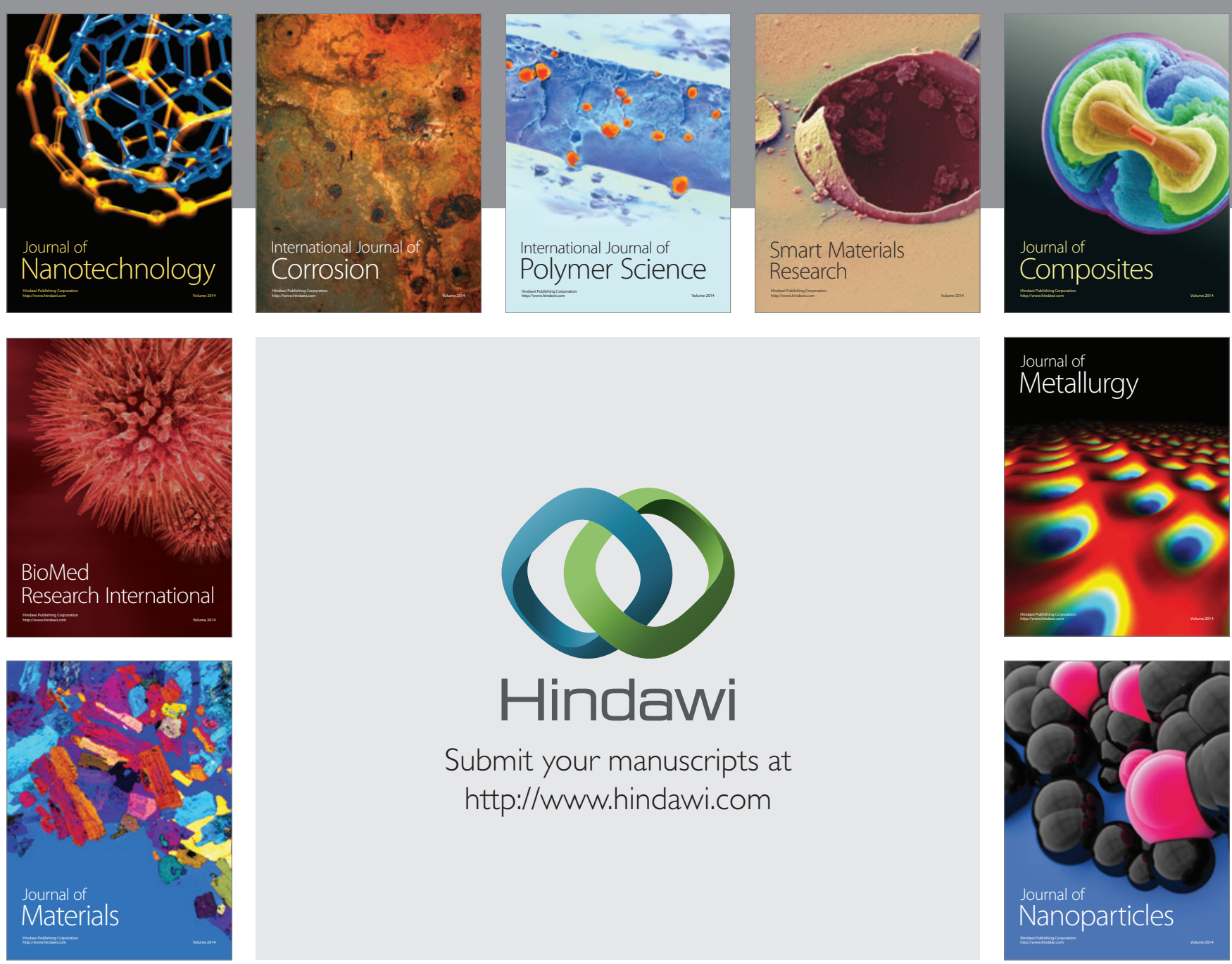

Submit your manuscripts at http://www.hindawi.com
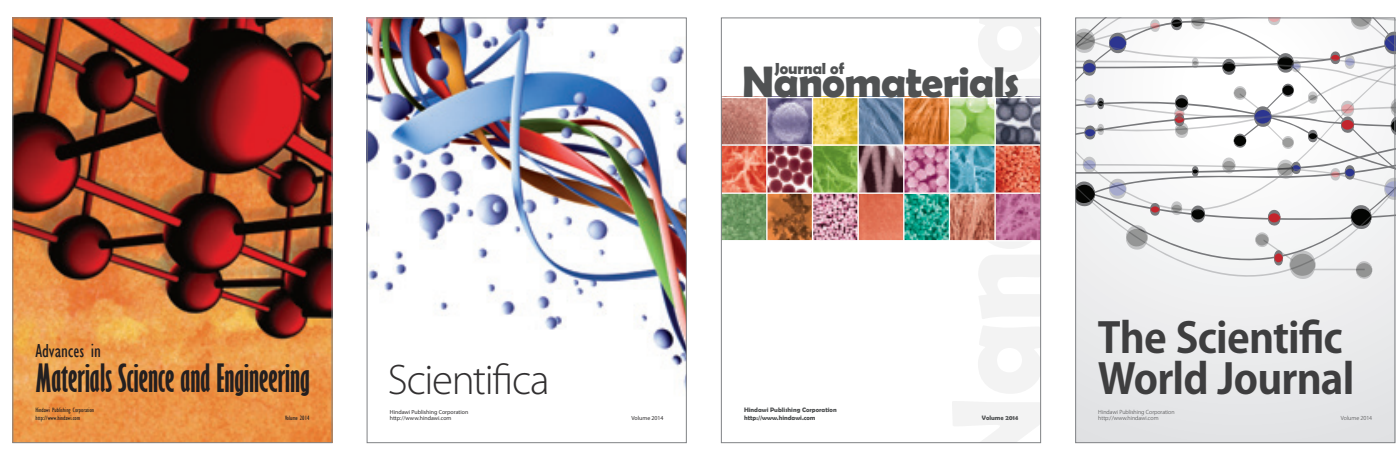

\section{The Scientific World Journal}
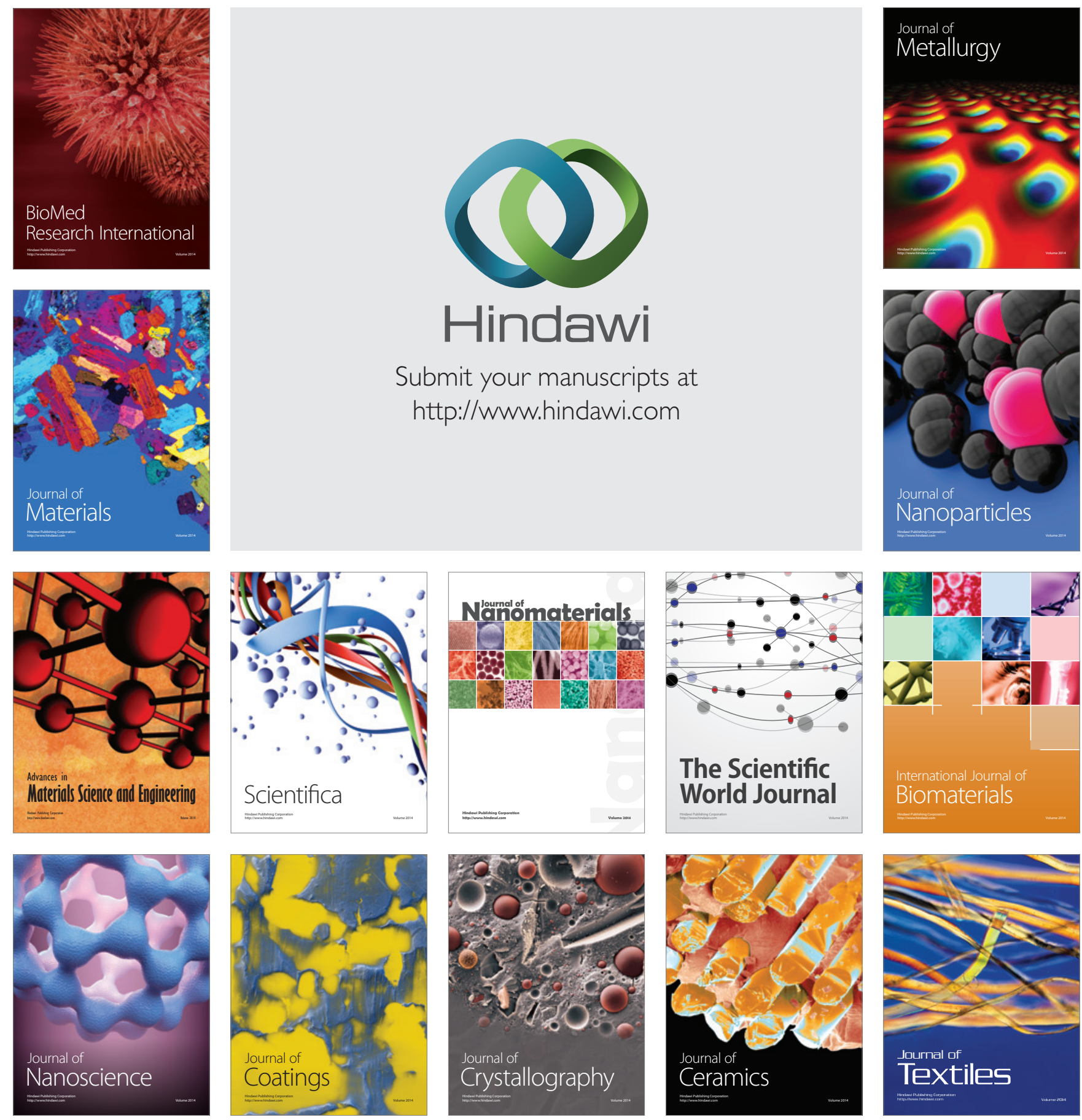